\title{
CALCIUM AND ITS USING FOR MODIFICATION OF ALSI7MG0.3 ALLOY FROM VIEW OF FINAL MICROSTRUCTURE AND HARDNESS
}

\author{
Natasa Naprstkova ${ }^{1}$, Pavel Kraus ${ }^{1}$, Dana Stancekova ${ }^{2}$ \\ ${ }^{1}$ J. E. Purkyne University in Usti nad Labem, Czech Republic; ${ }^{2}$ University of Žilina, Slovakia \\ naprstkova@fvtm.ujep.cz,kraus@fvtm.ujep.cz,dana.stancekova@fstroj.uniza.sk
}

\begin{abstract}
Treatment of metal alloys is one of the ways to affect the quality and properties of the material. This also applies to aluminum alloys. Nowadays so-called silumins are often used One of them is also the alloy AlSi7Mg0.3, which is used for production of casting parts. The article describes one of the experiments in the area of modification of Al-Si alloys, realized at the Faculty of Mechanical Engineering of Jan Evangelista Purkyně Univesity in Ústí nad Labem, when the influence of calcium (Ca) on alloy AlSi7Mg0.3 was experimentally studied. Calcium is one of the elements, which is possible to be used for changing of aluminium alloys properties, but as it is possible to read in literature, the view on its influence differs, whether it is bad or good. The alloy was modified with various amounts of calcium. Experimental quantities of calcium were 0.05 , $0.2,0.3$ and 0.4 percent by weight. Experimental alloys were made from individual components. The final microstructure of each alloy and their hardness were analysed. For this the confocal laser scanning microscope LEXT OLS 3100 and hardness tester Ernst AT 250X were used, which are available at the FME. Experimental samples were machined, too and tool wear of using cutting inserts was analysed, and the shape of the chip was measured. It was realized with the light microscope Olympus SZX 10. The presented experiments and measurements are part of the extensive research undertaken at the Faculty of Mechanical Engineering at Jan Evangelista Purkyně University in Ústí nad Labem.
\end{abstract}

Keywords: aluminium, modification, alloy, machining.

\section{Introduction}

For various reasons, as it is generally known, alloys are adjusted (alloyed, inoculated and modified). Of course, this also applies to aluminum alloys. These reasons are, eg., to improve the physical and technological properties. At the Faculty of Mechanical Engineering in this context various experiments were implemented just with aluminum alloys. One of them is research in the effect of different amounts of selected elements to certain aluminum alloys. One of the investigated elements is calcium $(\mathrm{Ca})$, which can be used as the modifying element, in particular of Al-Si alloys. This improves the morphology of silicon in the alloy. It also improves the castability of aluminum alloys. But also it has negative effects, e.g., deterioration of the homogeneity of the resulting microstructure and is therefore considered as a harmful element. As the research shows, the important thing is the amount of it [1-4].

Modification of aluminum alloys is a process, by which the melt is deliberately modified by various elements in order to influence the mechanism of eutectic solidification. Modification changes the morphology and size of crystals of silicon (in the case of Silumin), causing a significant increase in the mechanical properties compared to unmodified alloys. Large size silicon of crystals has lower strength properties of Al-Si alloys. Strength and plastic properties of the modified alloys are therefore higher in comparison to unmodified alloys. Modification in this case is meaningful only for aluminum alloys with a silicon content of more than $5 \%[1 ; 5-7]$.

Therefore, in this area at the FME JEPU there are the experiments realized. With this specific alloy, one of which this article describes, when the experimental alloy was AlSi7Mg0.3, which is alloy from the group of Al-Si (silumin). Silumins are among the major casting alloys based on aluminum. They are intended for the production of shaped castings for casting into sand or metal molds or for pressure die casting. They have high corrosion resistance, low coefficient of linear shrinkage and satisfactory mechanical properties [8-10].

Alloy AlSi7Mg0. 3, with which the experiment was carried out, contains $92.7 \%$ aluminum, $7 \%$ silicon and $0.3 \%$ magnesium according to the standard. It is used in many technical applications, such as automotive, aerospace, engineering and food industry. It has greatest application in the automotive industry, casts from it, such as cylinder heads, engine blocks, wheel rims and components for trucks. Because the alloy contains a certain amount of silicon, it can be achieved by modification with good mechanical properties $[1 ; 11]$. 
With this specific alloy the influence of calcium amount on the final microstructure and hardness has been besides studied.

\section{Materials and methods}

The role of $\mathrm{Ca}$ as a modification modifier for Al-Si alloys is often very much discussed (in both positive and negative terms), especially in terms of its quantity. For this reason, extensive experiments are being carried out at the FME JEPU, part of which is an experiment, where it is examined, how big amount of $\mathrm{Ca}$ has positive effects on the AlSi7Mg0.3 alloy, and when this is no longer appropriate $[9 ; 10]$.

For the experiment were made castings from alloy AlSi7Mg0.3 for each type of alloy. The casting groups were made at the FME from individual components. There was not master alloy applied. Five casting groups were made, which were alloyed by varied amounts of calcium $(0,0.05,0.2,0.3$ and 0.4 wt. \%). The castings were carried out gravitationally into a suitable metal mould of the required dimensions and the equipment was used, which is available at the FME JEPU. All the mould dimensions had to comply with requirements for the size of the casting, in order to be able subsequently carry out other planned experiments.

For checking the correct chemical composition of the samples the spectrographic analysis was carried out. The composition of the samples was examined by the equipment INNOV Delta X, several randomly selected samples were analysed for comparison by using the equipment Q4 Tasman. The chemical composition of castings corresponded to the standard [12-14].

For microscopic observation of the microstructure metallographic samples were made. A confocal laser scanning microscope Lext OLS 3100 (Fig. 1) was used for the microstructure analysis [15-17].

The next step was to measure the hardness of the experimental alloys. Brinell hardness was measured. The Brinell hardness of samples was measured according to the standard EN ISO 6506-1 on the hardness tester Ernst AT 250X (Fig. 2). The hardness measurement was performed by injection a ball with $2.5 \mathrm{~mm}$ diameter at a load of $612.916 \mathrm{~N}$ for 10 seconds. The hardness was always measured at the top and bottom of each cast. Twelve measurements were made on each sample from the center to the edge of the sample [18].

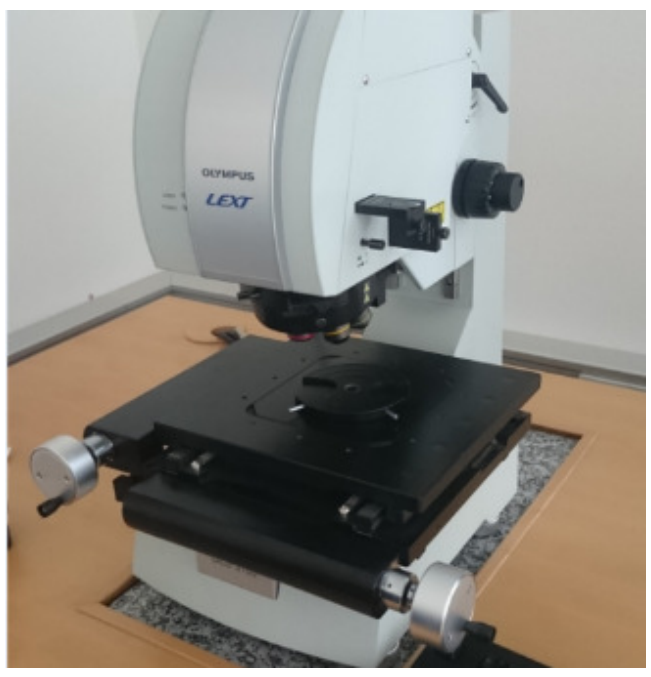

Fig. 1. Microscope Olympus LEXT 3100

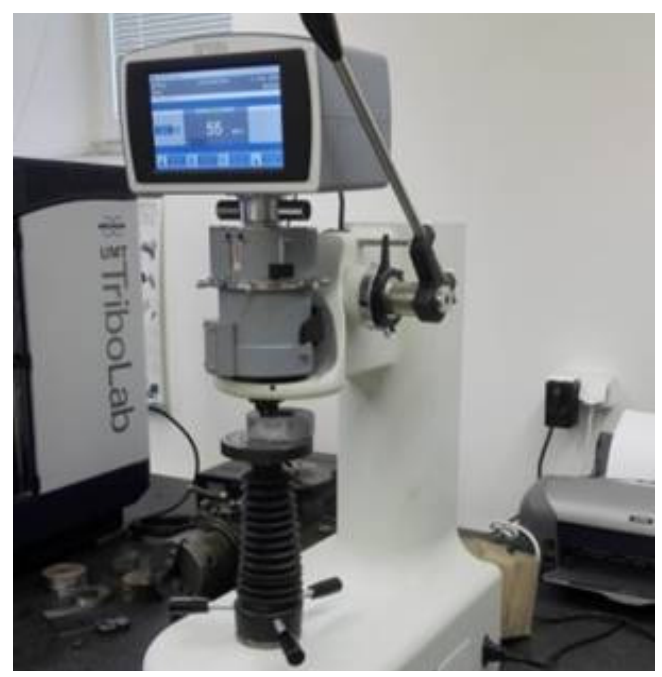

Fig. 2. Hardness tester Ernst AT 250X

\section{Results and discussion}

For all groups of castings samples for microstructure analyses were prepared.

In the microscopic analysis, the microstructure of the AlSi7Mg0.3 alloy was first examined in unmodified state (Fig. 3 and 4). The microstructure of this alloy AlSi7Mg0.3 (a group of subeutetic silumins) is formed by a substitution solid phase $\alpha$ solution and a eutectic consisting of a mixture of a solid solution $\alpha$ and crystals of pure silicon. In the microstructure long needle-like formations of dark 
colour were evident. Silicon was excreted here in the form of large hexagonal plates, which were longsliced in the cut and were sharply bounded.

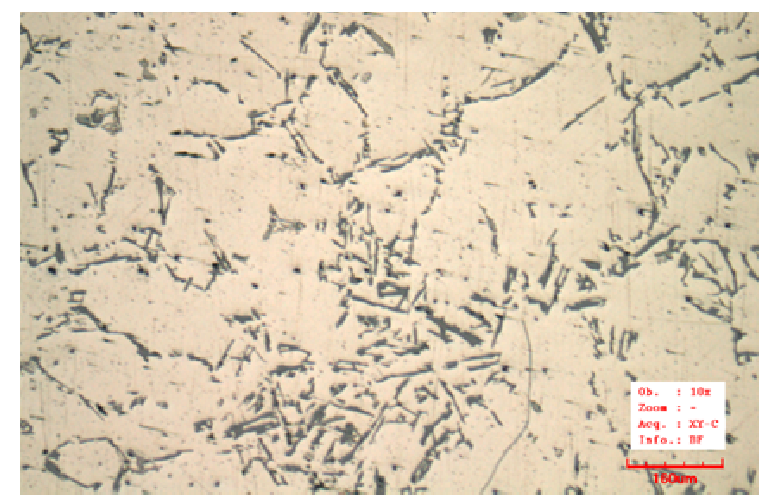

Fig. 3. 0 wt. \% Ca in alloy (mag. 100x)

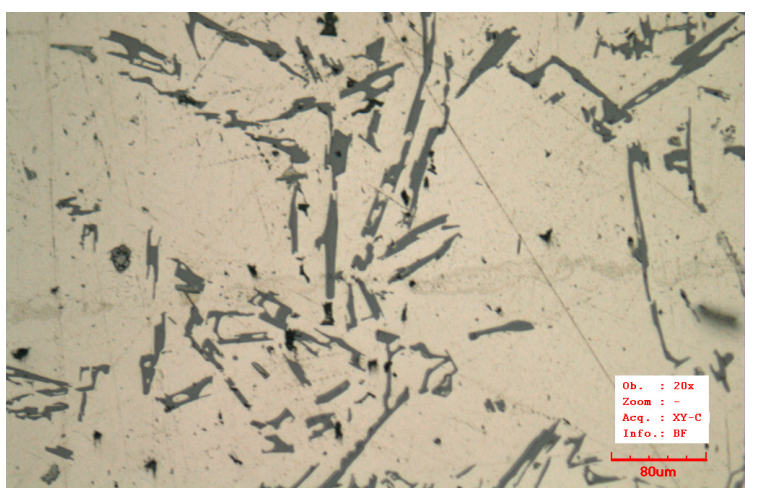

Fig. 4. 0 wt. \% Ca in alloy (mag. 200x)

In Fig. 5 and 6 the resulting alloy mcrostructure is modified with 0.05 wt. \% Ca. There is a clear difference between the alloy microstructure modified and unmodified, where eutectic silicon is excluded in the form of smaller plates of silicon compared to unmodified alloy. These cutting boards have the shape of shorter needles, which are slightly rounded around the circumference. Excluded plates are noticeably smaller than for the unmodified alloy.

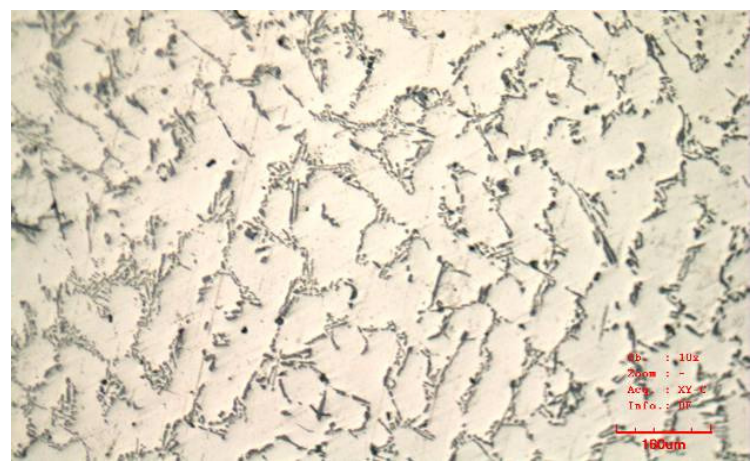

Fig. 5. 0.05 wt. \% Ca in alloy (mag. 100x)

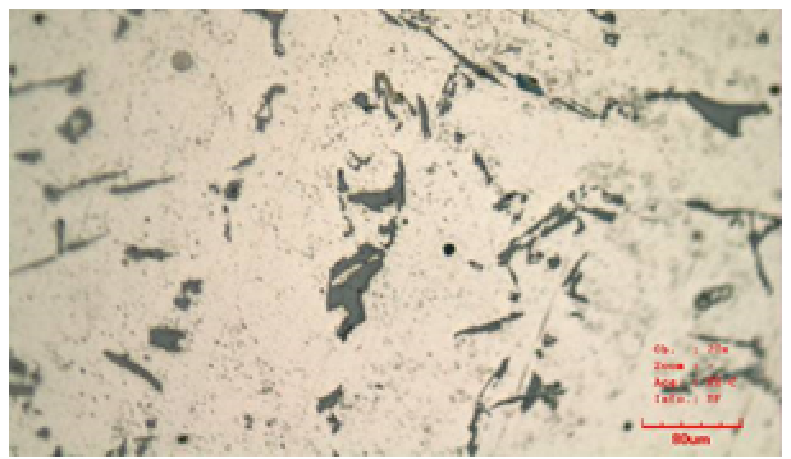

Fig. 6. 0.05 wt. \% Ca in alloy (mag. 200x)

In Fig. 7 and 8, the resultant alloy microstructure is modified with 0.2 wt. $\%$ Ca. Here, again, the effect of calcium is observed, when the rounding of the edges of needle-like shapes is more pronounced and the needles are less knowledgeable than in the amount of $0.05 \mathrm{wt} \% \mathrm{Ca}$. The hexagonal plates were smaller and appeared in the form of small rods and needles on the metalographic cut. In some parts of the microstructure, the incidence of interdendritic porosity and the thickening of a part of eutectic silicon were evident.

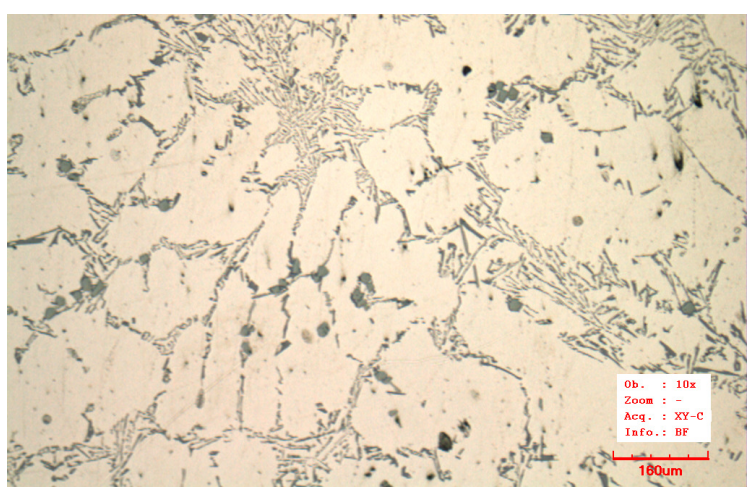

Fig. 7. 0.2 wt. \% Ca in alloy (mag. 100x)

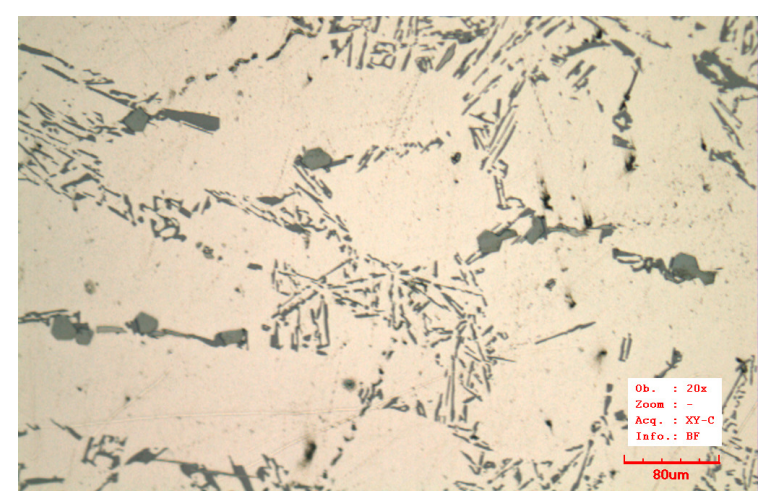

Fig. 8. 0.2 wt. \% Ca in alloy (mag. 200x)

In Figures 9 and 10, the microstructure of AlSi7Mg0.3 alloy is modified with 0.3 wt. \% Ca. With a further increase in calcium content, there were changes in the microstructure, with which greater 
gasification and thus porosity, the occurrence of thickened silicon particles with irregular geometrical shape at the edge of the dendrites and the occurrence of intermetallic compounds in the form of dark needles.

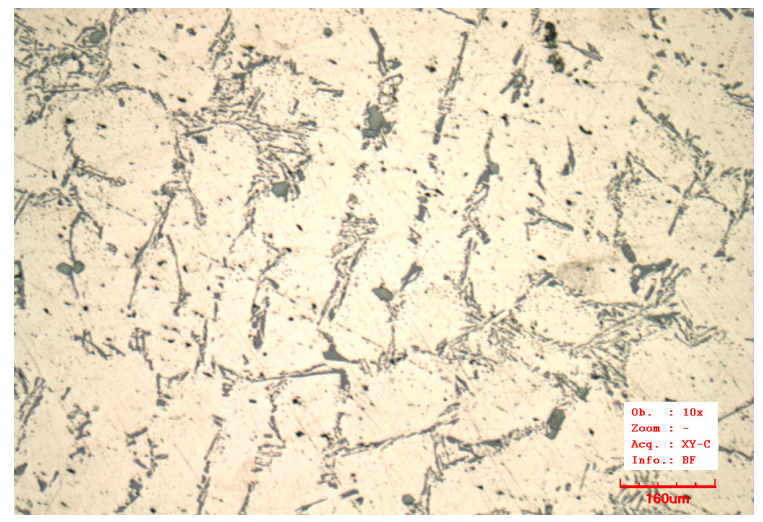

Fig. 9. 0.3 wt. \% Ca in alloy (mag. 100x)

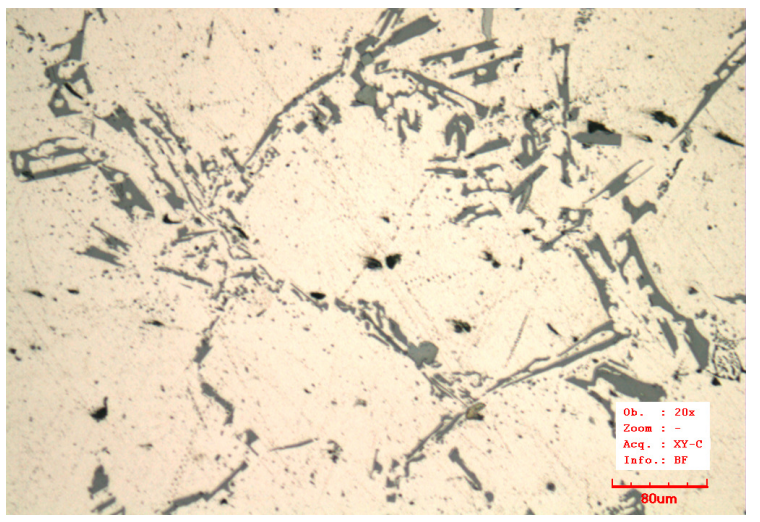

Fig. 10. 0.3 wt. \% Ca in alloy (man. 200x)

In Figures 11 and 12 the alloy microstructure is modified with 0.4 wt. \% Ca. At this Ca content, the sharpness and elongation of the needles and the further occurrence of sharpened silicon particles were clearly evident. In addition, it was possible to observe a larger amount of the coarsening particles of silicon. Here, the microstructure from the point of view of the modification requirement is completely unsatisfactory.

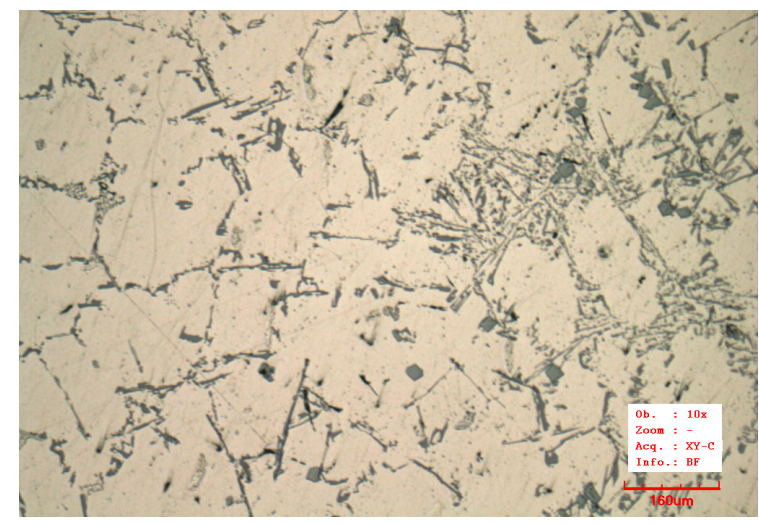

Fig. 11. 0.4 wt. \% Ca in alloy (mag. 100x)

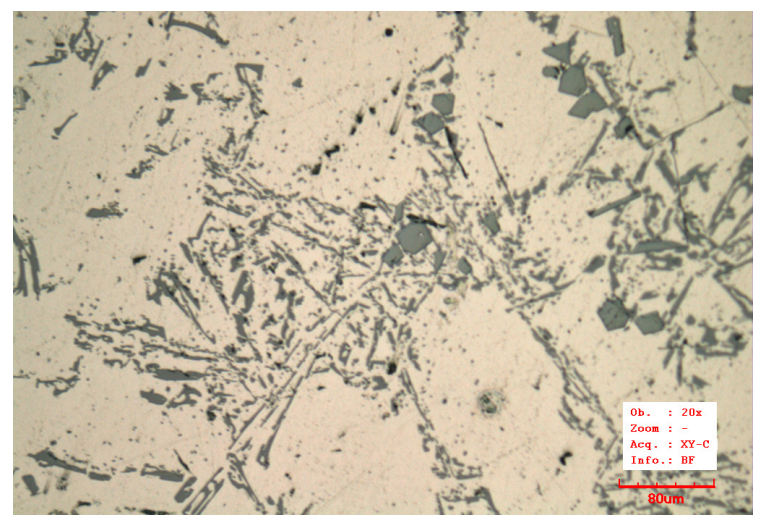

Fig. 12. 0.4 wt. \% Ca in alloy (mag. 200x)

Increasing the amounts of $\mathrm{Ca}$ also saw increasing porosity of the castings.

Furthermore, the hardness of the experimental alloys was evaluated. Fig. 13 shows a graph with average hardness values for each type of alloy.

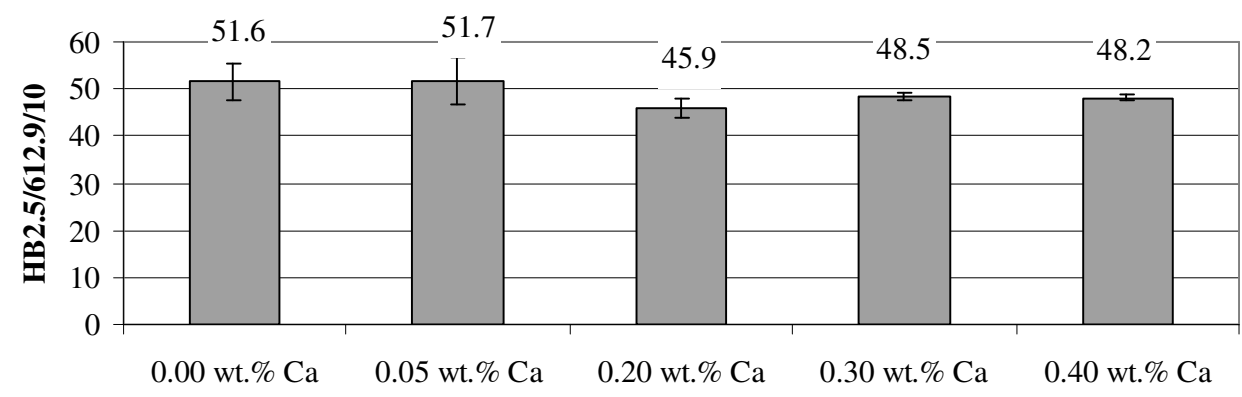

Type of AISi7Mg0.3 alloy

Fig. 13. Hardness of experimental alloy

From the average values it is clear that the samples modified with higher $\mathrm{Ca}$ have a lower hardness than the alloy without modification. Here, the measured values ranged from 45 to $49 \mathrm{HB}$, 
which is somewhat less hardness than in according with the standard for this material (50-55 HB). Material unmodified and modified only with $0.05 \mathrm{wt}$. \% Ca reached hardness in the standard (51.6 unmodified alloy, 51.7 modified alloy), there were practically no hardness differences for these types of alloy. This phenomenon can be attributed to the fact that increasing Ca content occurs in the alloy greater gasification (the comparison was observable and according to the literature this is one of the poor Ca properties) and the castings were realized by gravity casting, which also negatively affects the resulting porosity of the castings. This is likely to negatively affect the internal homogeneity of the resulting materials. The amount of bubbles in the melt create porosity and thus reduction in the hardness of the material. Overall, it can be stated that increasing the amounts of calcium has a rather negative effect on the resulting alloy hardness.

\section{Conclusions}

From the results of the microscopic analysis it was possible to confirm the modifying effects of $\mathrm{Ca}$ on the AlSi7Mg0.3 alloy microstructure. The modifying effect was mainly due to a certain refinement of the microstructure of the eutectic silicon and to the reduction of its particles. As the $\mathrm{Ca}$ content increased, there was a greater occurrence of thickened particles of eutectic silicon, which at a greater size had a negative effect on the mechanical properties of the casting (reducing ductility). In the analysis, the difference between the unmodified and modified samples was apparent at first glance. The change in microstructure was evident at $0.05 \mathrm{wt} . \% \mathrm{Ca}$, when there was a certain refinement of the entire microstructure compared to the unmodified alloy. For a content of $0.2 \mathrm{wt} \% \mathrm{Ca}$ the cast microstructure was even finer and the silicon particles were even smaller according to the metallographic scraps. But with further increases of the Ca content, silicon particles and intermetallic phases have grown. The regular feature was always a coarser microstructure at the top of the casting than at the bottom of the casting. This was probably due to cooling of the casting and removal of heat from it.

Another analysis was the Brinell hardness measurement, which was performed by pushing a 2.5 $\mathrm{mm}$ diameter ball at a load of $612.916 \mathrm{~N}$ for 10 seconds. On each casting, measurements were always made on the top and bottom of the cast. Depending on the measured values, it was apparent that the samples unmodified and modified at $0.05 \mathrm{wt} \% \mathrm{Ca}$ achieved practically the same hardness. For modified alloys 0,02 wt. \% Ca and more, a hardness drop was observed in the range of 45 to $49 \mathrm{HB}$, a hardness somewhat less than is the standard for this material (50-55 HB). The lower hardness of the measured castings was most likely due to the casting method used, since, as mentioned above, castings exhibited a high degree of porosity (gasification and interdentric, too).

For greater relevancy of the results, it is necessary to change the method of production of castings, especially in connection with experiments with the amount of $\mathrm{Ca}$. Although this element improves the alloying ability of the alloy, it also generally increases gasification in the casting, which increases with the still used casting method.

\section{Acknowledgements}

The authors are grateful for the support of grant No. CZ.1.05/4.1.00/11.0260 EDIMARE and SGS FME JEPU in Ústí nad Labem for 2018.

\section{References}

[1] Michna S., Lukac I., Ocenasek V., Koreny R., Drapala J., Schneider H., Miskufová A. and coll. Encyklopedie hliníku (Encyclopedia of aluminum). 1st edn. Adin, Prešov, 2005 (In Czech).

[2] Bolibruchova D., Tillova E. Zlievarenske zliatiny Al-Si (Cast alloys Al-Si). Univeristy of Zilina, EDIS, 2005 (In Slovak).

[3] Vojtech D. Kovove materialy (Metallic materials). VSCHT Praha, Praha, 2006, 140 p. Metallic materials. VSCHT Praha, Praha, 2006, 140 p. (In Czech).

[4] Kusmierczak S. Udage of Technical Equipment in Teaching Technical Subjects. In: International Scientific Conference Engineering For Rural Development, vol 14, 2015. pp. 748-752.

[5] Weiss V. Prodlouzení modifikacniho ucinku pomoci beryllia u slitiny AlSi7Mg0.3 (Extending the modification effect of beryllium on AlSi7Mg0.3 alloys). Slevarenstvi, no. 5-6, 2012 (In Czech). 
[6] Strihavkova E., Analysis of New Type Al-Si-Mg Alloy Structures with Diferent Contents of Ca Due to Chemical Properties. In: International Scientific Conference Engineering For Rural Development, vol 16, 2017, pp. 521-527.

[7] Lipinski T. Mechanical Properties of AlSi12 Alloy with Aluminium Bronze. In: International Scientific Conference Engineering For Rural Development, vol 16, 2017, pp.1064-1068.

[8] Cais J. Kraus P., Lysonkova I. Influence of the Homogenization Temperature on the Microstructure and Properties of AlSi10CuNiMgMn Alloy. Advances in Science and Technology-Researche Journal, vol. 11, no. 1, 2017, pp. 104-110.

[9] Michna S., Naprstkova N. The Mechanical Properties Optimizing of of Al-Si Alloys Precipitation Hardening and the Effect on the Character of the Chip. Acta Metallurgica Slovaca, vol. 18, no. 3, 2011, pp. 193-199.

[10] Strihavkova E., Weiss V., Michna S. Study of the structure and fluidity of alloy of the Al-Si-Mg system with a different calcium content. Metallurgist, vol. 56, no. 9-10, 2013, pp. 708-713.

[11] Michna S., Kusmierczak S. Technologie a zpracovani hlinikovych materialu (Technology and Processing of Aluminium Materials). JEPU. Usti nad Labem, 2008 . (In Czech).

[12] Michna S., Kusmierczak S. Prakticka metalografie (Practical metallography). FME JEPU, Ústí nad Labem, 2012, 245 p. (In Czech).

[13] Formanek J., Kucerova L., Tochylin M. The Hazards of Defects and Poor Quality of Aluminium Materials. In: Proceedings of 24th Internatioanl Conference on Metallurgy and Materials METAL, 2015, pp. 1552-1557.

[14] Grzincic M., Lukac I. Identification of Intermetallic Phases in the Alloy AlSi6Cu4 Manufacturing Technology, vol. 14, no. 2, 2014, pp. 160-166.

[15] Michalcova A., Vojtech D. Structure of Rapidly Solidified Aluminium Alloys. Manufacturing Technology, vol. 12, no. 13, 2012, pp. 166-169.

[16]Lipiński T. Microstructure and Mechanical Properties of the AlSi13Mg1CuNi Alloy with Ecological Modifier. Manufacturing Technology, vol. 11, no. 11, 2011, pp. 40-44.

[17] Weiss V., Strihavkova E. Influence of the homogenization annealing on microstructure and

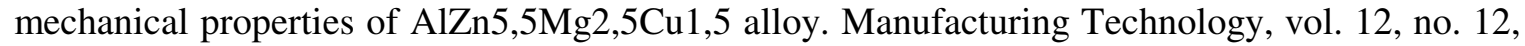
2012, pp. 297-302.

[18] Kucerova L. The effect of two-step heat treatment parameters on microstructure and mechanical properties of 42SiMn steel. Metals, vol. 7, no. 12, 2017, p. 573. 